\title{
Adrian C. Pirtea. “St. Isaac of Nineveh's Gnostic Chapters in Sogdian : The Identification of an Anonymous Text from Bulayïq (Turfan)"
}

Florence Jullien

\section{(2) OpenEdition}

Journals

Édition électronique

URL : https://journals.openedition.org/abstractairanica/54239

DOI : 10.4000/abstractairanica.54239

ISSN : 1961-960X

Éditeur :

CNRS (UMR 7528 Mondes iraniens et indiens), Éditions de l'IFRI

Référence électronique

Florence Jullien, « Adrian C. Pirtea. "St. Isaac of Nineveh's Gnostic Chapters in Sogdian : The Identification of an Anonymous Text from Bulayï (Turfan)" », Abstracta Iranica [En ligne], Volume 42-43 | 2021, document 38, mis en ligne le 30 décembre 2021, consulté le 19 décembre 2022. URL http://journals.openedition.org/abstractairanica/54239; DOI : https://doi.org/10.4000/ abstractairanica.54239

Ce document a été généré automatiquement le 19 décembre 2022.

Tous droits réservés 


\title{
Adrian C. Pirtea. "St. Isaac of Nineveh's Gnostic Chapters in Sogdian : The Identification of an Anonymous Text from Bulayïq (Turfan)"
}

\author{
Florence Jullien
}

\section{RÉFÉRENCE}

Adrian C. Pirtea. "St. Isaac of Nineveh's Gnostic Chapters in Sogdian : The Identification of an Anonymous Text from Bulayïq (Turfan)" in Madalina Toca, Dan Batovici (eds.). Caught in Translation: Studies on Versions of Late Antique Christian Literature. Leiden: Brill, 2020, p. 85-103.

1 Cet ouvrage réunit une dizaine de contributions traitant du phénomène de traduction de la littérature chrétienne ancienne et de réception dans le contexte culturel de la nouvelle langue, dans une perspective de mise en dialogue. La transmission des auteurs grecs, spécialement des Cappadociens, en milieu syriaque ou arménien, comme les traductions arméniennes d'auteurs syriaques (Jacques de Saroug), ou encore le passage de textes latins en éthiopien ou dans les langues de l'Orient témoignent du seul point de vue littéraire de l'ampleur du phénomène d'interculturalité au Proche et MoyenOrient dans l'Antiquité tardive et de son importance dans la construction des sociétés.

Dans cet article, après avoir retracé la diffusion de l'œuvre du mystique syro-oriental Isaac de Ninive en Occident, et ce grâce au rôle joué par les traductions en grec, en géorgien et en arabe effectuées au monastère palestinien de Mār Saba, l'A. examine sa réception du côté oriental. Le ms. E27 (anciennement C2), rédigé en sogdien, contient un précieux témoin de la Deuxième partie, peu connue, des Kephalaia Gnostica d'Isaac (II. 
3). C'est sans doute autour $d u I^{e}-X^{e}$ siècle que cette traduction fut réalisée au monastère de Xipang près de Bulayïq dans le Turkestan chinois. Ce fragment avait déjà été édité et traduit par Niicholas Sims-Williams en 1985 (The Christian Sogdian Manuscript C2, [Berliner Turfantexte XII], Berlin : Akademie-Verlag, p. 69-77), mais restait encore non identifié. Il témoigne de l'importance de l'héritage spirituel des Pères syriaques pour les communautés syro-orientales des provinces "de l'extérieur".

\section{AUTEURS}

FLORENCE JULLIEN

CNRS, CeRMI, Paris 